\title{
Challenges of Educators in the Context of Education Reform and Unrest: A Study of Southern Border Provinces in Thailand
}

\author{
Kanita Nitjarunkul ${ }^{1}$, Ekkarin Sungtong ${ }^{1}$ \& ${\text { Peggy } \text { Placier }^{2}}^{2}$ \\ ${ }^{1}$ Prince of Songkla University, Thailand \\ ${ }^{2}$ University of Missouri, U.S.A. \\ Correspondence: Ekkarin Sungtong, Department of Educational Administration, Faculty of Education, Prince of \\ Songkla University, Pattani Campus, Thailand. Tel: 66-89-8114-814. E-mail: blackovation@hotmail.com
}

Received: July 28, 2014 Accepted: August 3, $2014 \quad$ Online Published: August 22, 2014

doi:10.5539/ass.v10n18p232

URL: http://dx.doi.org/10.5539/ass.v10n18p232

\begin{abstract}
This qualitative study aimed to identify challenges of educators faced with education reform and violent unrest that has taken place in five Southern provinces of Thailand, as well as leadership characteristics that emerged in this context. Participants were 21 educators from primary schools in Pattani, Yala, Narathiwat, Songkhla and Satun provinces. A purposeful selection was employed for participant recruitment of the study. Data collection methods were semi-structured interviews and related official document analysis. The study revealed that challenges of educators related to education reform were managing curriculum, increasing students' reading competency, coping with work overloads, and managing limited budgets. Challenges related to social unrest were dealing with instructional management, coping with feelings, and ensuring safety. Leadership characteristics that emerged in response to these challenges were becoming patient, dedicated, and adaptive; guiding changes in instructional methods; and building collaborations with related stakeholders.
\end{abstract}

Keywords: education reform, unrest, southern border provinces of Thailand, challenges

\section{Introduction}

In many countries, education reform is defined as a national agenda that aims to develop an educated population. In economic terms it contributes to sustainable development of the country, because the population is an important resource for development. In political terms, it contributes to development of informed citizens who consider the interests of the nation. Thus, education reform is regarded as one of the tools and processes that will help to bring change and development to members of the society, particularly in schools where there are students, teachers, educational personnel as well as communities or other stakeholders that play an important role in driving or creating changes. However, the dimension of education reform in each country or each school context is different. It depends on the culture and the management system or even the history of the nation. As an economist, North (1990) said that, "an essential aspect to reform or develop the organization relies on various dimensions and balance factors as well as historical and environmental contexts" (p. xx). This quotation is consistent with the dimensions of education reform in Thailand, which has been brought about by social structural and economic changes as well as greater competition on the world stage. Thus, education reform in Thailand needs urgently to prepare the population to be persons who can learn on their own and persons who have abilities to develop themselves continuously. Education must also prepare the nation to have a potential equal to countries in the region and the world. The driving motivation of education reform in Thailand has been specific in its frame and concept down to the level of concrete practices, because the New Constitution of 1997 focused on human rights to receive an equal education. This concept was also in the National Education Act of 1999 (Revised 2002) which focused on the direction of developing quality of education, human, educational management as well as media and technology to promote education. Primary schools, both public and private, in the Southern border provinces are one of the organizations involved in educational management which cannot resist reform in response to educational policy, to fulfill the expectation for change and bring good things in society via the organization. When the expectation for people to create changes in the organization is set up, it can create challenges that drive the change in many dimensions. The basic dimensions are target, need and shared values. This is especially true in the case of the policy of education reform. After the official announcement over the country, various stakeholders who were involved in education reform, such as teachers 
and school administrators, needed to acquire a better understanding of education reform policy concepts as well as the emergence of leadership in education, in order to shape concrete responses to education reform policy. However, education reform actors and stakeholders, as members of organizations, also confront the cultural dimension in their areas, particularly the beliefs, values and norms with a long history for people in the Southern border provinces societies, including Pattani, Yala, Narathiwat, Songkla and Satun. These provinces have distinctive cultural identities which differ from other regions of the country. The most distinctive identity and culture are found in the three southernmost provinces consisting of Yala, Pattani and Narathiwat. Eighty percent of the population are Muslims who have been concerned about preserving their culture and value highly their identity for a long time. The restraint for educational reform, in their minds, is the Islamic religion (Farrungsang, 2008). Because of the above reasons, it can be seen that the path to education reform, especially in the context of the five Southern border provinces, has educational, social, religious and cultural dimensions which are linked together firmly and are highly dynamic. The dimensions are complicated and sensitive. Thus, education reform cannot achieve the purpose and intention of the policy quickly. Particularly, there is a convergence of current problems in the three Southern border provinces, especially the problem of unrest which has occurred continually in the area. "In Southern Thailand, Islamic separatist groups are fighting to establish an independent state in the three southern most border provinces and, over the last decade, they increased attacks on teachers, school principals, and school buildings" (Brooks, 2014, p. 1). Deep South Watch (2014) reported that over 6,000 died.

In the conflict, 10,000 people were wounded from January 2004-July 2014 and the incidents of violence, the fatalities and injuries tended to be higher apparently since July 2007. The particular convergence of education reform and unrest in Southern border provinces is an uncommon phenomenon. Nevertheless, it is the challenge issue facing educators and stakeholders, especially educators in the elementary schools in the five southernmost border provinces which are responsible for teaching at the basic education level (Grade 1-6). Schools cannot avoid being confronted with the challenges of these two events. Organizational leaders or school administrators and teachers must develop clear strategies and plans in accordance with the intention of education reform, the cultural context of people in the area and students' needs. They must make plans in response to education reform despite the unrest in the region.

\section{Research Objectives}

The objectives of the study were to identify challenges facing educators in the Southern Border Provinces of Thailand in response to both national education reform mandates and local unrest, and to identify the characteristics of leadership that emerged in this context. The research questions were:

1) What challenges for educators in the Southern border provinces are associated with national education reform?

2) What challenges for educators are associated with the unrest in the Southern border provinces?

3) What characteristics of educational leadership emerged in response to the convergence of education reform and social unrest in this setting?

\section{Perspectives of the Study}

This is a study of the transformation of policymakers' intentions for education reform (Hall \& McGinty, 1997) in a setting where implementers face far more than the "usual" dilemmas. As in many nations, Thailand's government has adopted major educational reforms in recent years, aimed at extending access to schooling, raising academic expectations, and entailing more uniform curricula and educational quality. Expressed intentions for reform are economic development (especially through math, science, advanced training) and democratic citizenship. Educational reformers also recognize the importance of developing a shared moral vision while preserving local cultures. This would be a tall order for educators in any nation, but educators in the southern provinces face additional challenges. Educational policies emanate from the capital of Bangkok, distant from the setting of this study. In the southern provinces, especially those bordering Malaysia, the vast majority of citizens are Muslim. An ongoing issue for schools has been Muslim objections to a curriculum traditionally steeped in Buddhist beliefs. Much negotiation has gone into addressing these conflicts and making curriculum changes; agreements even include providing government support for Muslim schools (Sungtong, 2009). In addition, this area has been torn by political tensions and violence. Based on the level of local unrest, the National Police Operators Center has divided areas in three Southern border provinces into three zones: green, yellow and red. A red zone means that there is violence in the area or the area is under the influence of insurgents. Some people in these zones are threatened by violence and want government protection, while others are inclined not to cooperate with the government in any way. During June 2009 public opinion polls by the Center 
for Conflict Studies and Cultural Diversity (CSCD) of Prince of Songkla University assessed the emotional and social impacts of the unrest among a sample of 2,000 people from the region including Muslims, Buddhists and Christians. Findings showed that 22 percent were personally and emotionally affected as friends or relatives of people who died, were wounded or disappeared because of the unrest. The violence affected educators both as community members and as specific targets, because the perpetrators targeted public schools as symbols of the Thai state (Deep South Watch, 2009). Therefore, educators in the setting of this study faced extraordinary pressures to both comply with national reform expectations and cope with unpredictable danger. The researchers wondered how they were managing these pressures and what leadership characteristics were emerging in this context.

\section{Research Methodology}

This qualitative research is a case study (Yin, 2005) of education reform in the unrest in Southern Thailand. The participants were 21 educators including teachers, supervising teachers, and school administrators who varied in terms of gender, educational background, religion, age and who worked in primary schools in the five southernmost provinces of Thailand. The researchers used purposeful selection to choose the participants, based on their experience of working in these provinces as well as their knowledge of education reform and unrest. The researchers interviewed the participants using a semi-structured interview protocol and used relevant documents including legislation and government reports, school manuals, meeting documents and data from online databases to develop a rich context for participants' accounts. The in-depth interviews conducted in Thai language took about 1.5 to 2 hours, considered an appropriate length for a qualitative interview (Seidman, 1998). The lead researcher interviewed participants face-to-face at their schools or other places depending on their sense of security. The researchers transcribed and then analyzed the data using grounded theory techniques (Strauss \& Corbin, 1990; Charmaz, 2006), coding data to find patterns or themes that represented phenomena or events in the participants' accounts. Data analysis was inductive, moving from particular to general, generating themes from the data and then generalizations or theoretical descriptions of the phenomenon. The researchers used methods recommended by Lincoln and Guba (1985) to maximize trustworthiness: Prolonged engagement, peer debriefing, triangulation of data, member checking, rapport building and collaboration. Patton (2002) said that the researcher not only collects data from informants but also identifies their needs as collaborators, thus creating a relationship that helps the researcher get accurate and reliable information. In addition, researcher reflexivity was essential to the study. The researchers are long-time residents of the southern border provinces who understand the cultural backgrounds of the participants and the tension under which they have been working in recent years.

\section{Results}

Challenges resulting from education reform policies, challenges tied to unrest, and leadership practices that emerged in the face of these challenges are as follows:

\subsection{Challenges Resulting from the Adoption of National Education Reform Policy}

\subsubsection{Implementing Required Curriculum Changes}

The educators reflected that schools were experiencing many problems in terms of curriculum especially applying curriculum toward developing students' learning to be knowledgeable, good and moral persons. In fact, the reform could not put these concepts into practice realistically. Because the curriculum contained too much content, it finally caused difficulties in instructional management. It also challenged many schools which were trying to apply effective curriculum. Moreover, the school curriculum itself did not meet the central curriculum in some points.

\subsubsection{Dealing with the Effects of Students' Low Reading Competency}

The students' low literacy competency in Southern border provinces was the key issue. In comparing to other regions of the country, achievement in students' reading in the Southern border provinces was lower than students in other regions. Moreover, the problem of attitudes towards the use of Thai language also affected students' low reading competency. Moreover, students were familiar with local Malay language and there was little opportunity to practice reading Thai language. For these reasons students did not use Thai language as a tool of learning.

\subsubsection{Coping with Work Overload}

Elementary schools in Southern border provinces were confronted with the challenge of work overload produced by education reform. This problem affected the effectiveness of instructional and organizational management strategies. Increasing work directly affected effective management. It caused teachers to neglect developing 
themselves and created trouble dealing with instructional management.

\subsubsection{Managing Limited Budgets}

Budget was another major issue in the education reform era. The state tried to find methods or measures to reform funding policy and supported capitalization grants to school management. There was also a policy for communities to participate in the promotion of education or donate to educational needs. These efforts were insufficient in some schools or some areas. Therefore, this issue was a challenge in terms of how to help schools with limited budget to be adequate as well as to build understanding with the communities and parents to participate in raising capital for managing schools. On the other hand, schools without adequate budgets must find measures for managing limited budgets efficiently.

\subsection{Challenges Due to Unrest}

\subsubsection{Dealing with Instruction}

Schools in basic education in southern border provinces, particularly Pattani, Yala and Narathiwat obviously were confronted with the challenges of dealing with instructional management. The unrest affected the potential of instructional management of personnel in the schools. They were worried about the safety of personnel. In addition, educators in the organization did not have enough time to work effectively because of limited hours they could be at school. This was different from educators working in Songkla and Satun, who were not directly influenced by the unrest.

\subsubsection{Coping with Feelings}

The findings suggested that schools were greatly affected in terms of fear and lack of morale, encouragement and happiness in working for personnel in the three southern border provinces, consisting of Pattani Yala and Narathiwat. Educators in these areas were worried, fearful, lacking morale, encouragement and happiness more than educators working in Songkla and Satun. These two were affected slightly, but it was an indirect effect without affecting morale, encouragement or happiness in working.

\subsubsection{Ensuring Safety}

The results from this study suggested that organizations, especially basic education organizations, coping with challenge in terms of security of lives and property of personnel staff in organizations and educators, especially in Pattani, Yala and Narathiwat were the main target groups since the continuously unrest beginning January, 2004. The people tend to continue receiving impact. This could be considered as a challenge to organizations and educators in building safety to life and property. However, some educators in Songkla might experience some security risk, but less than three Southern border provinces. Satun was the least affected province.

\subsubsection{Building Relationships}

The unrest in the Southern border provinces created organizational challenges for educators in the Southern border provinces in terms of building relationships and positive feeling together. These findings clearly indicated that some educators were confronted with challenges in building relationships, especially between personnel staff in schools and between schools and communities during the unrest. The lack of opportunities to build relationships and lack of trust with each other was a result of past events.

\subsection{Characteristics of Educators' Leadership}

Leadership that emerged in the Southern border provinces were: 1) reinforcing positive behavior through patience, dedication, and enthusiasm, 2) changing instructional methods to be more child-centered and localized, and 3) as difficult as it might be, building collaboration with stakeholders. Despite their challenges, they reported some success stories in all three of these areas. Tolerance toward demands for educational change was an expression of the traditional Thai values of duty and responsibility. An essential leadership skill was also to keep people's spirits high in spite of the challenges. Teachers and administrators demonstrated instructional leadership in terms of knowledge of curriculum and instructional methods to enhance students' achievement. However, even though educators were trying to demonstrate collaborative or participative leadership, it could not be done at some levels because of cultural and linguistic differences as well as violence in the Southern border provinces.

\subsubsection{Reinforcing Positive Behavior through Patience}

This study suggested that an obvious natural approach to educational leadership in the organization in southern border provinces in response to education reform during the unrest was to demonstrate patience and exertion as well as an attempt to adapt and build enthusiasm in job performance despite the work overload and increased unrest. Those expressions were positive characteristics of natural leadership in an effort to change the reform 
which required support from all parties through body and mind as well as to raise awareness and recognition of the importance and value of the reform.

\subsubsection{Changing Instructional Methods to Be More Child-Centered and Localized}

Changing instructional methods was an essential characteristic of educators' natural leadership under the jurisdiction of elementary schools in Southern border provinces. These people were trying to express the importance of education reform policies by changing instructional methods which showed that the main focus of education reform was to manage instruction in accordance with educational policy, especially the National Education Act 1999 (Revised 2002). Another aspect of educators' emerging leadership was trying to emphasize child-centered teaching methods by integrating knowledge and local wisdom in teaching. Teachers must focus on the students' interests and consider the wisdom of the local people in each area.

\subsubsection{Building Collaboration with Stakeholders}

Building collaboration with stakeholders was another characteristic of educators' natural leadership in the Southern border provinces. The education reform and unrest in the area were catalysts which forced educators to build collaboration in order to advance the agenda of reform as well as to solve problems resulting from the unrest especially the damage caused by violence in the area.

\section{Discussion}

Scholars and educational institutions mentioned about challenges of education reform in different perspectives. Dealing with curriculum management during education reform was inefficient and did not achieve the goals of being smart, good and happy persons. It was probably because the instructional system was still focused on memorizing. The curriculum did not encourage students to think (Office of Education Reform, 2001) or focus on the instructional system rather than the learning system (Nakhontab, 2002). The study results also suggested that if applying curriculum was incorrect or defective, failure would finally occur (Utharanan, 1994). This would lead to organizational challenges, particularly in schools which were expected to provide instruction in accordance with the curriculum. As for the students' low reading competency, Sungkarat (2001, p. 61) remarked that students were not aware of value of Thai language learning." Most of them used local Malay language in daily life and Thai language was used to communicate with only teachers. Finally, it caused social problems because students when entered the wider society, they would suffer communication losses (Ministry of Education, 2008). In terms of teachers' work overload, Krathumket (2003) and Ministry of Education (2006a) accepted that teachers in education reform era still had a work overload and the problem needed to be seriously addressed (Nakhontab, 2002). There should a way be to reduce teacher's work load so that they can carry out responsibility for their duties effectively (Ministry of Education, 2004). The Office of the Education Council (2004) noted that managing limited budgets in schools was a difficult problem. This result was consistent with Ministry of Education Office (2004) that education reform caused budget limitations. Sometimes, it caused teachers to use their own money to support learning activities in spite of these teachers having economic limitations (Wiratchai, Wongwanich, \& Ruengtrakul, 2004).

Facing challenges from unrest was a unique phenomenon for educators in Southern border provinces of Thailand. Schools could not provide full education because instruction sometimes must be stopped, causing students' low achievement (Jitpiromsri et al., 2008). Scott (1992) said that the core of the organization in the schools is instruction. It is a key component of organizational development. Scott explained that instruction was a core technology, so if the core of the organization was affected, it must effect the organization's growth as well. The findings suggested that educators, especially in Pattani, Yala and Narathiwat who worked in the red zone were worried, fearful, lacking morale, encouragement and happiness more than educators working in Songkla and Satun which were in the yellow zone. Jitpiromsri et al. (2008) explained that the unrest in Southern border provinces such as ambush and burning schools caused teachers, school administrators and students, to lack a feeling of morale, to the point that finally they decided to move to another place. Therefore, schools became low on staff that had abilities to develop organizations efficiently. Lunenburg and Ornstein (2008) said that the atmosphere in schools indicated the potential of schools, because they were open systems. So, a school could not avoid the various problems occurring in the surrounding area. The temporary solution was to try to create a closed system of organization but it was not good for organization because it affected the instructional management. Thus, what schools could do was to try to strengthen people's health by building reinforcement and motivation for people in the organization. These things appeared to be obvious, in that the government was trying to motivate people in the organization, especially in the three Southern border provinces, by providing risk bonuses of 2500 Baht $(\$ 78) /$ month, getting double retirement age and special privileges as well as increasing morale and encouragement to people in the Southern border provinces. Trying to build organizational 
atmosphere could help organizations reduce problems of fear, lack of morale and encouragement, but it was not sustainable solution. In Southern Thailand, ensuring safety for teachers, school administrators and personnel was a significant task of school in unrest. The Deep South Watch (2009) reported that the cruel violence in the area continually occurred and the impact on schools could not be avoided because the dimensions of social problems in the Southern border provinces were complex. Farrungsang (2008) stated that the three Southern border provinces were a special area. Problems and social conditions, in the past, created distrust between government officials and people in the Southern border provinces. Unfortunately, when the unrest emerged, schools were confronted with challenges in building relationships, especially between personnel staff in schools and between schools and communities. Therefore, the lack of building relationships among people or creating wide gaps in relationships among the majority of people in the Southern border provinces who were Islamic and the minority who were Buddhists could lead to cultural conflict (Martin, 2002).

Despites educators in Southern border provinces of Thailand encountered various challenges from education reform and unrest; they tried to perform positive characteristics of natural leadership that fitted the events and context of the area. The educators confronted with the complex tasks and security problems clearly demonstrated their understanding of the situation and awareness of the changing environment (Katz \& Khan, 1978). As Arunyawet (2001) stated, adaptation in the changing environment is critical. Educators in the education reform era must be patient, tolerant to the barriers and devoted to work. They cannot escape the problems. Ruebling et al (2004) urged that the key to success for educational management was the focus on instruction. The teachers and administrators must demonstrate instructional leadership in terms of knowledge and understanding of curriculum and efficient instructional methods development to enhance students' achievement levels, which was the primary expectation of parents and communities. Mulford (1996) (cited in Lahui-Ako, 2001) said that educational change could be transferred by expression of educators' instructional leadership by both teachers and school administrators which must be focused on the success of students by providing instruction to meet students' needs. School administrators and teachers must build active collaboration to develop curriculum, instruction and evaluation. That leadership was the expression of shared-instructional leadership (Marks \& Printy, 2003). Another aspect of educators' emerging leadership was trying to emphasize child-centered teaching methods by integrating knowledge and local wisdom in teaching. Although there was an awareness of child-centered teaching methods, there was little change according to the report of Nakorntab (2002). He mentioned that teachers emphasized memorizing. Most teachers still did not change their teaching behavior. This was consistent with Chongsatityoo's study (2000) which found that most teachers try to focus on child-centered teaching methods but it had little success because the education reform was difficult and must be done gradually. An attempt to create cooperation with relevant authorities of educators showed an expression of collaborative leadership. Rubin (2002) stated that collaborative leadership focuses on building relationship or responsibility for the obligations to the organization's goals. Moreover, cooperative leadership also focuses on building relationships and sharing power with someone else and other organizations by using administrative and communication skills. Collaborative leadership would focus on maintaining relations of individuals to achieve integration objectives of the organization as well as focus on the participation in decision-making among stakeholders (Coleman, 2003). Building collaboration between schools and the community could help increase efficiently the management of teachers and administrators. But it requires the correct procedures and skills in building relationships (Rubin, 2002). Kaewdaeng (2001) said that building collaboration in the education reform era could be considered very important. School leaders must create network and build relationships with different groups to collaborate in education reform. However, building collaboration between organizations and communities could not be done smoothly due to unrest which directly affected educators in terms of security risks (Wisalaporn, 2009). In addition, cultural participation in education between schools and local communities lacked aggressive work. That was consistent with the findings of the Ministry of Education (2006b). The pattern of education in education reform was not diverse and did not meet the students' needs. Most schools would only focus on formal education. Individuals and various social institutions had less participation in education. The private sector did not take serious participation in education reform (Ministry of Education, 2006a). These concepts reflected that even though educators, both teachers and school administrators, were trying to demonstrate collaborative leadership, it could not be done in some levels because of cultural and social dimensions and violence in the Southern border provinces that occurred continuously.

\section{Conclusions}

Because of the different cultural context, it is difficult to pinpoint one western "leadership theory" that best describes practices that have emerged in southern Thailand (Marks \& Printy, 2003). Coping with the deep conflicts in this area surpasses glib recommendations of western "multicultural education" or "culturally relevant 
pedagogy," for example. This situation also goes far beyond the "context of change" Fullan (2001) envisioned. Thai cultural and moral values of responsibility and duty support the persistence and efforts of educators in this context, but understanding of cultural, linguistic and religious differences requires extraordinary effort, particularly when faced with the demand to simultaneously improve achievement scores. Moreover, longstanding problems on the region are beyond the capacity of schools alone to address. The situation also demands leadership that recognizes the emotional and psychological toll on educators and communities. The context taxes those in leadership preparation at universities in Southern Thailand, such as the one where the lead researchers work, to develop a way to prepare educators for their work. Such adaptations, as well as interventions to support educators in the field, are underway.

\section{Acknowledgements}

The researchers would like to thank Prince of Songkla University for the grant support. Significantly, we are indebted to our participants including teachers, supervising teachers, and school administrators in Southern Thailand who were involved in this research project. We also appreciate comments and suggestions of our colleagues, Asst. Prof. Dr. Wasant Atisabda, Faculty of Education, Prince of Songkla University, Pattani Campus, Prof. Dr. Margaret Grogan, School of Educational Studies, Claremont Graduate Universities, U.S.A., Associate Prof. Dr. Brendan Maxcy and Asst. Prof. Dr. Thu Suong Thi Nyuyen, School of Education, Indiana University-Purdue University Indianapolis (IUPUI), U.S.A.

\section{References}

Arunyawet, T. (2001). Professional administrators in the era of regional educational service area. Academic Journal, 4(2), 17-18.

Brooks, M. C. (2014). School principals in Southern Thailand: Exploring trust with community leaders during conflict. Retrieved July 19, 2014, from http://www.academia.edu/7638125/School_principals_in_Southern_ Thailand_Exploring_trust_with_community_leaders_during_conflict\#

Charmaz, K. (2006). Constructing grounded theory: A practical guide through qualitative analysis. Thousand Oaks, CA: Sage.

Chongsatityoo, C. (2000). The heart of reform is thinking to change. Sanpatiroob, 3(29), 54-61.

Coleman, M. (2003). Gender in educational leadership. In M. Bundrett, N. Burton, \& R. Smith (Eds.), Leadership in Education (pp. 36-52). London: Sage. http://dx.doi.org/10.4135/9781446215036.n3

Deep South Watch. (2009). Summary of six year-Southern fires: Dynamic insurgency and building imagination of the violence. Retrieved January 9, 2010, from http://www.deepsouthwatch.org/node/728

Deep South Watch. (2014). An inconvenient truth about the Deep South Violent conflict: A decade of chaotic, constrained realities and uncertain resolution. Retrieved July 12, 2014 from http://www.deepsouthwatch.org/node/5904

Farrungsang, B. (2008). The research in educational policy of the government in Southern border provinces (1997-2007). Journal of Education, Prince of Songkla University, Pattani Campus, 19(2), 29-43.

Fullan, M. (2001). Leading in a culture of change. San Francisco, CA: Jossey-Bass.

Hall, P. M., \& McGinty, P. J. (1997). Policy as the transformation of intentions: Producing program from statute. The Sociological Quarterly, 38(3), 439-467. http://dx.doi.org/10.1111/j.1533-8525.1997.tb00487.x

Jitpiromsri, S., Lertpipat, D., Poontrap, A., \& Chawmaithong, S. (2008). Political marginality with use of violence and politics of identity in Southern border provinces. Research Report of Faculty of Political Sciences, Prince of Songkla University, Thailand.

Kaewdaeng, R. (2001). Institutional administrator models and reform of learning and teaching. Bangkok:V.T.C. Communication, Ltd.

Katz, D., \& Kahn, R. L. (1978). The social psychology of organization (2nd ed.). New York: Wiley.

Krathumket, P. (2003). Problems of school curriculum implementation of pilot and network schools under the jurisdiction of Department of General Education Pranakornsriayudhaya Province. Pranakornsriayudhaya.

Lahui-Ako, B. (2001). The instructional leadership behaviour of Papua New Guinea high school principals: A provincial case study. Journal of Educational Administration, 39(3), 233-265. http://dx.doi.org/10.1108/0 9578230110392875

Lincoln, Y. S., \& Guba, E. G. (1985). Naturalistic inquiry. Newbury Park, CA: Sage.

Lunenburg, F. C., \& Ornstein, A. C. (2008). Educational administration: Concepts, and practices (5th ed.). 
Belmont, CA: Wadsworth.

Marks, H., \& Printy, S. M. (2003). Principal leadership and school performance: An integration of transformational and instructional leadership. Educational Administration Quarterly, 39(3), 370-397. http://dx.doi.org/10.1177/0013161X03253412

Martin, J. (2002). Organizational culture: Mapping the terrain. Thousand Oaks, London: Sage.

Ministry of Education. (2004). Academic conference on learning reform research. Bangkok: Office of Research and Educational Development.

Ministry of Education. (2006a). Summary report of brainstorming seminar on follow-up and education reform evaluation: Educational administration and management. Bangkok: Office of Educational Management Evaluation.

Ministry of Education. (2006b). Follow-up report on operational results of education reform strategies in accordance with the cabinet resolution on December, 31, 2005. Bangkok: Prikwan Graphic Com, Ltd.

Ministry of Education. (2008). Model of Thai instruction for prathomsuksa 1 (Grade 1) and prathomsuksa 4 (Grade 4) in the three Southern border provinces. Bangkok: Prikwan Graphic Com, Ltd.

Nakorntab, A. (2002). Report of Thai education status towards people (2003): Breaking through the knot of education reform. Bangkok: Office of Educational Management Evaluation.

North, D. C. (1990). Institutions, institutional change, and economic performance. New York, NY: Cambridge University Press. http://dx.doi.org/10.1017/CBO9780511808678

Office of Education Council. (2004). Education in Thailand 2004. Bangkok: Office of the Education Council.

Office of Education Reform. (2001). Thai education reform: In parents' perspectives. Bangkok: Pimdee.

Patton, M. Q. (2002). Qualitative research \& evaluation methods (3rd ed.). Thousand Oaks, CA: Sage.

Rubin, H. (2002). Collaborative leadership: Developing effective partnerships in communities and schools. Thousand Oaks, CA: Corwin Press.

Ruebling, C. E., Stow, S. B., Kayona, F. A., \& Clarke, N. A. (2004). Instructional leadership: An essential ingredient for improving student learning. The Educational Forum, 68(3), 243-262. http://dx.doi.org/10. 1080/00131720408984636

Scott, W. R. (1992). Organizations: Rational, natural, and open system (3rd ed.). Englewood Cliffs, NJ: Prentice Hall.

Seidman, I. (1998). Interviewing as qualitative research: A guide for researchers in education and the social sciences (2nd ed.). New York: Teachers College, Columbia University.

Strauss, A., \& Corbin, J. (1990). Basics of qualitative research. Thousand Oaks, CA: Sage.

Sungkarat, W. (2001). Past, present and future of private Islamic schools (Pondok) in Southern border provinces. Unpublished Master's Thesis in Educational Administration. Chiangmai University, Thailand.

Sungtong, E. (2009). Strategic leadership in the multicultural society: A review of theory and practice. Journal of Education, Prince of Songkla University, Pattani Campus, 20(1), 1-16.

Utharanan, S. (1994). Systematic instructional techniques. Bangkok: Mitsiam Publishing.

Wiratchai, N., Wongwanich, S., \& Ruengtrakul, A. (2004). Evaluation of learning reform results based on the National Education Act, B.E. 2542. Journal of Research Methodology, 17(2), 215-230.

Wisalaporn, S. (2009). Status of educational Management in the Three Southern border provinces (3rd ed.). Bangkok: V.T.C. Communication Com, Ltd.

Yin, R. K. (2005). Case study research: Design and method (3rd ed.). Thousand Oaks, London: Sage.

\section{Copyrights}

Copyright for this article is retained by the author(s), with first publication rights granted to the journal.

This is an open-access article distributed under the terms and conditions of the Creative Commons Attribution license (http://creativecommons.org/licenses/by/3.0/). 